\title{
Os espaços simbólicos e a construção de estratégias no Shopping Popular Oiapoque
}

\section{The symbolic spaces and the constructions of strategies in the Oiapoque popular shopping}

\author{
Alexandre de Pádua Carrieri ${ }^{1}$ \\ Ivana Benevides Dutra Murta ${ }^{2}$ \\ Milena Cristiane Nascimento Mendonça ${ }^{3}$ \\ Carolina Machado Saraiva de Albuquerque Maranhão ${ }^{4}$ \\ Alfredo Rodrigues Leite da Silva ${ }^{5}$
}

\section{Resumo}

O objetivo deste artigo é evidenciar em que sentido as mudanças espaciais (físicas e simbólicas) transformaram as estratégias de gestores da economia informal, quando estes foram retirados das ruas e passaram a atuar como lojistas no Shopping Popular Oiapoque, o primeiro da cidade de Belo Horizonte/MG. Com base na abordagem da estratégia como prática social e à luz das categorias sociológicas "casa" e "rua" de DaMatta (1991) acerca da sociedade brasileira, assume-se que, no estudo em questão, o significado simbólico atribuído ao espaço é fator fundamental à análise das estratégias como prática social. Os dados foram coletados por meio de entrevistas semi-estruturadas, realizadas no ano de 2006, e examinados por meio da análise de conteúdo. Como conclusão, observou-se que, no locus do estudo, o espaço simbólico do shopping como "rua" e da rua como "casa" coexiste com o espaço simbólico do shopping como "casa" e da rua como "rua". Os dois espaços simbólicos envolvem o fazer estratégia dos sujeitos que atuam no shopping. Os sujeitos alinhados com o primeiro buscam resgatar práticas anteriores perdidas ao entrar no shopping. Os sujeitos alinhados com o segundo buscam novas práticas: para eles o shopping não é apenas uma "casa", mas uma nova "casa", na qual se situam com novas práticas sociais.

Palavras-chave: espaço simbólico; estratégias, shopping popular; construção social.

\begin{abstract}
It is intended through this article to enlighten how the spatial changes (symbolic and geographical) transformed the business strategies of the informal economic organizations, when they were moved from the streets to a popular shopping named Oiapoque, the first of this kind at Belo Horizonte/MG. Trough the perspective of strategy as a social construction and based on the sociological categories of "rua" (street) and "casa" (home) of DaMatta (1991), about the Brazilian society, it is assumed that the symbolical meaning of the shopping is a fundamental factor on the building strategy process as a social construction. Primaries data were collected trough semi-structured interview and the technique of subject analysis was used. In conclusion, it was perceived that the locus of this research is understood both as "rua" (street) and "casa" (home) by the respondents. The first group tried to sustain their former strategic practice on the new geographical place, the shopping Oiapoque, because they didn't feel it as their "casa" (home). The second group, otherwise, built new strategies practices, based upon the conception as the shopping as a new "casa" (home).
\end{abstract}

Keywords: symbolic space; strategies; popular shopping; social construction.

\footnotetext{
${ }^{1}$ Doutor em Administração pela Universidade Federal de Minas Gerais. Professor Adjunto da Universidade Federal de Minas Gerais FACE/UFMG. Endereço: Rua Newton, 275, Bairro Santa Lúcia. Minas Gerais/Belo Horizonte -CEP: 30360-200 - Brasil - E-mail: alexandre@cepead.ufmg.br

${ }^{2}$ Estudante de graduação em Turismo na Universidade Federal de Minas Gerais. Bolsista PROBIC/FAPEMIG do Centro de Pós-Graduação e Pesquisa em Administração CEPEAD/FACE/UFMG. Endereço: Rua Junquilhos, 1019, apto 202 B. Jardim América - Belo Horizonte - MG - Brasil - CEP: 30460-010. E-mail: ivanabenevides@yahoo.com.br

${ }^{3}$ Estudante de graduação em Administração na Faculdade de Ciências Econômicas da Universidade Federal de Minas Gerais - FACE/UFMG. Endereço: Rua Pará de Minas, 60, 207, Bairro Pe. Eustáquio.- Brasil - CEP.: 30730-440 - E-mail: milenacristiane@yahoo.com.br

${ }^{4}$ Doutoranda em Teoria Crítica e Estudos Organizacionais do CEPEAD/UFMG. Bolsista de Doutorado da Fundação de Amparo à Pesquisa do Estado de Minas Gerais/FAPEMIG.Endereço: R. Nancy de Vasconcelos Gomes, 277, apt 402 - Sagrada Família - Belo Horizonte/MG - Brasil - CEP: 31030-070. E-mail: cms@cepead.face.ufmg.br

${ }^{5}$ Doutor em Administração. Professor da FUCAPE Business School (www.fucape.br). Endereço: Av. Fernando Ferrari, 1358 - Goiabeiras/Vitória - Brasil - CEP: 29075-010. E-mail: arls@cepead.face.ufmg.br

Artigo submetido em julho de 2007 e aceito em outubro de 2007.
} 


\section{Introdução}

Nos anos 80 e 90, em face da reestruturação produtiva, do processo inflacionário e do aumento do desemprego, o setor informal no Brasil tornou-se peça-chave nos discursos do Estado (GONTIJO NETO; MACHADO, 2003). O setor informal passaria a ser visto como uma alternativa permanente para sanar os dissabores das crises econômicas, uma possibilidade, entre outras, de absorção da mão-de-obra excluída do mercado formal de trabalho.

Nas grandes cidades ocorreu um aumento dos processos de criptoeconomia, ou seja, um conjunto de atividades econômicas visando à complementação de renda, sobrevivência e/ou lucro, por meio da transgressão de regras econômicas, sociais, éticas e morais. Como exemplo, enumera-se o aumento do trabalho autônomo, terceirizado e, até mesmo, informal, ilegal - com ampliação das práticas de precarização do trabalho -, bem como da prostituição infantil, do tráfico de drogas, armas, e da corrupção (LIMA, 1985).

Ao mesmo tempo em que esse processo se amplia, o Estado busca formalizar parte desse setor informal, principalmente a partir de meados dos anos 90 (GONTIJO NETO; MACHADO, 2003). No caso particular da cidade de Belo Horizonte, a Prefeitura Municipal, a fim de abarcar os comerciantes informais - vendedores ambulantes, camelôs e "toreros" - que trabalhavam nas ruas, construiu espaços específicos denominados de "Shoppings Populares". Partindo-se desta constatação, o objetivo deste artigo é evidenciar em que sentido as mudanças espaciais (físicas e simbólicas) transformaram as estratégias de gestores da economia informal, quando estes foram retirados das ruas e passaram a atuar como lojistas do Shopping Popular Oiapoque, o primeiro da cidade de Belo Horizonte/MG.

Esse processo de mudança torna-se relevante enquanto elemento revelador das práticas e do modo de gestão de uma organização e, por conseqüência, das suas estratégias. Estas, por sua vez, rompem com a visão funcionalista para se tornarem frutos da dimensão simbólico-cultural, historicamente construída, na qual os significados que permeiam a sua construção estariam sujeitos a transformações ao longo do tempo (NKOMO; COX JUNIOR, 1996).

Dentro desse entendimento, para estudar as relações do fazer estratégia que envolvem os gestores inseridos no Shopping Popular Oiapoque, adotou-se, como prática social, a abordagem da estratégia. Nesta, autores como Jarzabkowski (2005) e Wilson e Jarzabkowski (2004) defendem que as práticas sociais bem como as inserções contextuais que as envolvem compõem a base do processo de fazer estratégia. Ao discutirem essa abordagem, os autores destacam a necessidade de um embasamento na teoria social que permita tratar da questão da inserção contextual dos sujeitos. Neste artigo, para esse embasamento, adotaram-se contribuições de DaMatta (1991) sobre a sociedade brasileira, com ênfase na sua elaboração das categorias sociológicas "casa" e "rua".

Para tratar da articulação dessa base teórica em torno do objetivo proposto, no sentido de alcançá-lo, o artigo está estruturado da seguinte maneira: inicialmente, são discutidas as propostas da estratégia como prática social e sua articulação com contribuições de DaMatta (1991) sobre a sociedade brasileira. Em seguida, apresentamse os aspectos metodológicos da pesquisa, o projeto do Shopping Popular da Prefeitura de Belo Horizonte, a análise dos dados e as considerações finais do estudo.

\section{A estratégia como prática social}

O campo dos estudos sobre estratégia inclui uma diversidade de paradigmas convergentes ou divergentes, capazes de polarizar as compreensões sobre o tema. Como destacam Carlomagno e Bruhn (2005), somente alguns pontos de convergência entre as abordagens são claramente observados, tais como as proposições de que: a estratégia diz respeito tanto à organização como ao ambiente; a sua essência é complexa; afeta o bemestar da organização; e envolve questões tanto de conteúdo como de processo. 
O termo "estratégia" é comumente utilizado em referência a cursos de ação, mas as propostas sobre as maneiras como estes devem ser tratados pelo pesquisador e pelo ator organizacional variam de uma abordagem para outra. Nesse sentido, Cancellier, Almeida e Estrada (2005) destacam o tema do monitoramento ambiental nos estudos sobre estratégia. Na mesma direção, Rebelo e Erdmann (2003) apontam que esse monitoramento abre espaço para desenvolvimentos dentro da questão da aprendizagem organizacional, mas que, ao se observar o campo dos estudos sobre estratégia, há um afastamento dessa possibilidade, pois muitas das concepções referentes a ela buscam a definição deliberada de ações futuras, baseando-se em dados do passado e projeção de cenários. Ou seja, em lugar de uma base para o desenvolvimento das pessoas na organização como um todo, o ambiente é tratado como uma informação para a deliberação de um planejamento futuro.

Essa preocupação com a ênfase excessiva na deliberação ganha legitimidade, na medida em que autores se aproximam de contribuições, para o campo, de Mintzberg (1978; 2004) e Mintzberg e Walters (1985). Os autores defendem a necessidade de tratar essa lógica deliberada, de formulação de uma estratégia pretendida, em conjunto com outra lógica, a de estratégia realizada, que se diferencia da primeira por incorporar, também, a formação de estratégias emergentes, surgidas na organização, a despeito da inexistência de uma deliberação anterior.

É nessa direção que se desenvolveu a chamada visão processual da estratégia, trabalhada por Mintzberg (1967) desde a década de 1960. Conforme o autor:

[...] a formação estratégica é definida simplesmente como um processo de tomar importantes decisões organizacionais (por exemplo, para reorganizar, desenvolver uma nova linha de produtos, embarcar em um programa de expansão). Estratégia é o conjunto dessas decisões, podendo evoluir na medida em que decisões independentes são tomadas ao longo do tempo, ou ser resultado de processos de formação de planos integrados (MINTZBERG, 1967, p. 71, grifo nosso).

Segundo Wilson e Jarzabkowski (2004), outro autor que se destaca dentro da chamada visão da estratégia como processo é Pettigrew (1977). Ao identificar o que chamou de "processo intencional", Pettigrew (1977) se volta para a percepção dos membros organizacionais. $\mathrm{O}$ autor explica que há uma percepção parcial em virtude de dilemas organizacionais específicos, capazes de aguçar a consciência dos membros organizacionais sobre a estratégia, o que permitiria pensá-la como um processo intencional. A despeito da percepção parcial, não existiriam dois tipos de estratégia, um deliberado e outro emergente, nem tampouco um processo de formulação e outro de formação. O que existe é um processo de construção político, inserido em diferentes contextos sociais que o afetam. Esse processo de fazer estratégia está em contínua transformação e pode se apresentar de maneira mais evidente - quando percebido como intencional - ou de maneira mais oculta - quando percebido como algo que emergiu sem uma intencionalidade direta. Mas, a despeito das diferentes percepções, as intenções e os interesses políticos, bem como as inserções contextuais, sempre permeiam o processo de fazer estratégia (PETTIGREW, 1977).

A visão processual de estratégia, incluindo a ênfase política oferecida por Pettigrew (1977), embasou o desenvolvimento do campo na direção da chamada abordagem da estratégia como prática. "O foco dessa abordagem está na estratégia como 'prática' social, em como os praticantes da estratégia realmente agem e interagem" (WHITTINGTON, 1996, p. 731; tradução nossa). Essa preocupação vai ao encontro do objetivo proposto neste artigo, uma vez que, nessa abordagem, a inserção contextual é reconhecida como elo que permeia as práticas sociais no fazer estratégia. Portanto, há espaço para a compreensão dos sentidos relacionados com essas inserções, o que levou à adoção da abordagem da estratégia como prática para nortear a investigação aqui desenvolvida.

Wilson e Jarzabkowski (2004) explicam que, sob essa ótica, a estratégia é apresentada como uma prática diária dos atores organizacionais e construída através da interação social. Para os autores, “[...] a estratégia não deveria ser concebida como um longo período de pensamento - formulação da estratégia -, seguido por um longo período de ação - implementação da estratégia, mas como um processo que entrelaça pensamento e 
ação" (WILSON; JARZABKOWSKI, 2004, p. 13). O fazer estratégia é compreendido à luz de contribuições da teoria social no que se refere às relações entre as práticas sociais dos sujeitos e suas inserções contextuais. Essa preocupação se justifica pelo fato de o fazer estratégia passar a ser visto como envolvido diretamente por essas práticas, numa visão em que pode ser conceituado como "a habilidade astuciosa para usar, adaptar e manipular os recursos que são empregados para se engajar na formação da atividade da estratégia ao longo do tempo" (JARZABKOWSKI, 2005, p. 34, grifo nosso). Esse é o conceito de fazer estratégia adotado neste artigo: destacando-se que, nessa concepção, a inserção contextual passa a ser algo inerente ao "fazer" (WILSON; JARZABKOWSKI, 2004).

Nesse sentido, ao investigar o fazer estratégia, as preocupações estão voltadas para "[...] os processos e as práticas detalhados que constituem as atividades diárias da vida organizacional e que se relacionam com os resultados estratégicos" (JOHNSON; MELIN; WHITTINGTON, 2003, p. 14). Wilson e Jarzabkowski (2004) ilustram parte dessas movimentações ao descreverem a estratégia organizacional como a combinação da animação com a orientação, elos essenciais à compreensão da estratégia. A animação expressa a idéia de uma ação viva, inserida em um contexto e com um reconhecido potencial de interação e construção; já a orientação refere-se a uma direção assumida a partir de construções oriundas da mencionada animação, o que compreende e ultrapassa os direcionamentos (como as metas e os objetivos) prescritos formalmente pelos gestores. $\mathrm{O}$ desafio é, então, encontrar suporte na teoria social que permita a compreensão do processo dessa combinação no fazer estratégia.

Como a investigação empírica deste artigo se concentra no contexto brasileiro, buscou-se essas contribuições nos estudos de DaMatta (1991) sobre a sociedade brasileira.

\section{Espaço simbólico - a casa e a rua}

O presente estudo utiliza as categorias sociológicas de DaMatta (1991) de maneira diferenciada. Procura-se analisar as representações compartilhadas e subjetivas dos ex-vendedores ambulantes da cidade de Belo Horizonte acerca do que é "casa" e do que é "rua", quando da transferência deles para os shoppings populares, e a interferência disso na construção das suas estratégias para o negócio que gerem.

Deve-se destacar que o uso das contribuições do autor em estudos organizacionais não é algo novo. As próprias categorias "casa" e "rua" foram utilizadas por diversos autores, como Ivo e Oliveira (2005), com foco em organizações familiares, e Soares (2000), para pesquisar o posicionamento mercadológico dos shoppings centers brasileiros. Mas não se tem notícia de seu uso como base para estudos na abordagem da estratégia como prática social. Ao adotar esse caminho, a intenção é reconhecer, nas contribuições de um pesquisador que buscou compreender a sociedade brasileira, categorias sociológicas que permitam investigar fenômenos sociais dentro dessa sociedade. No caso, o fenômeno do fazer estratégia.

Os conceitos "casa" e "rua" provêm de uma visão de sociedade que constrói sua própria realidade, diferentemente daquela que a concebe como uma instituição tomada por um conjunto de indivíduos. Isso significa que o sistema criado por esta sociedade é construído na interação de seus agentes, cujas normas precisam da aceitação das pessoas para se concretizarem, ao mesmo tempo em que estrutura seus comportamentos (DAMATTA, 1991).

Para o autor, a casa e a rua não designam somente espaços geográficos ou bens físicos e materiais. Quando se refere à sociedade brasileira, essas duas entidades compreendem valores morais, esferas de ação social, redutos éticos e instituições culturais capazes de gerar nos indivíduos sentimentos e imagens simbólicas sobre estes espaços. Elas só podem ser compreendidas adequadamente em oposição uma à outra, pois seu significado é também ideológico, percebido pelos contrastes e complementaridades.

A leitura da sociedade sob a perspectiva da casa ressalta a pessoa, com forte ênfase no aspecto emocional, englobando o espaço social e confundindo-se com ele. Mesmo havendo diferenças entre as pessoas, estas são 
vistas como "irmãos", já que pertencem à mesma instituição. Já na leitura das instituições sob a ótica da rua, valorizam-se os discursos rígidos e reformadores, que permitem a exclusão, a condenação e o banimento através do "idioma do decreto e da letra dura da lei" (DAMATTA, 1991, p. 22). Em casa somos os "supercidadãos"; na rua, somos "subcidadãos". O quadro a seguir apresenta as principais características associadas à "casa" e à "rua", contrapondo-se uma categoria à outra.

Quadro 1: Principais Características da "casa" e da "rua"

\begin{tabular}{ll}
\hline Casa & Rua \\
\hline Naturalização das relações sociais; & Reificação abusiva de conceitos e relações; \\
\hline Moral; & Fala totalizada por relações impessoais; \\
\hline Discurso "pré-político", alienado e ingênuo; & Lógica do sistema financeiro e capitalista; \\
\hline Laços de simpatia, hospitalidade e lealdade; & Lutas e discórdias; \\
\hline Pessoas; & Indivíduos; \\
\hline Ninho; & Fábrica; \\
\hline Local seguro e aconchegante; & Local perigoso; \\
\hline Relações comerciais justas. & Relações comerciais de exploração. \\
\hline
\end{tabular}

Fonte: Baseado em DaMatta (1991).

Nas oposições entre os diversos aspectos que norteiam as distinções entre a "casa" e a "rua", a construção social do espaço pode se dar com diversos significados entre os grupos. Isso foi percebido ao longo da pesquisa de campo, em que havia grande variedade de sentimentos expressos sobre o espaço do shopping popular. As diferentes vivências no mesmo espaço geravam formas diversas de se "ler" o ambiente, bem como estratégias diferenciadas entre os lojistas.

\section{Aspectos metodológicos}

A partir da base teórica apresentada, buscou-se investigar as relações entre as transformações das estratégias de gestores da economia informal e as mudanças espaciais (físicas e simbólicas). Para evidenciar as estratégias e as percepções dos sujeitos de pesquisa a respeito dos espaços simbólicos "casa" e "rua", foi realizada uma pesquisa qualitativa junto aos gestores que foram transferidos das ruas da cidade de Belo Horizonte/MG para o Shopping Popular Oiapoque.

A coleta de narrativas (BENJAMIN, 1994) dos sujeitos de pesquisa possibilitou a apreensão das histórias de vida, construídas a partir da perspectiva de seus próprios atores, cabendo ao pesquisador a lapidação dos dados, a fim de encontrar categorias semelhantes nas entrevistas realizadas, para, enfim, recontar a história destas organizações sob o enfoque de DaMatta (1991) acerca do espaço público e privado. O locus desta pesquisa envolveu o primeiro Shopping Popular criado em Belo Horizonte, o Oiapoque.

Foram realizadas 22 entrevistas, no período entre 15 de agosto e 23 de setembro de 2006 - todas gravadas e transcritas na íntegra. Portanto, os fragmentos apresentados neste artigo retêm os desvios, em relação à língua culta, verbalizados pelos respondentes. A intenção é evidenciar inserções contextuais destes na sociedade brasileira.

Durante o período de entrevistas, e após - até 16 de outubro do mesmo ano -, foram realizadas conversas informais e observações no local de atuação dos sujeitos de pesquisa. As entrevistas foram realizadas com o auxílio de um roteiro semi-estruturado (THIOLLENT, 1987), apenas com a finalidade de indicar o foco das questões a serem tratadas. As conversas e observações foram registradas em um diário de campo, a partir do qual foi possível obter dados adicionais para a análise. 
Como técnica de tratamento e exame de dados, utilizou-se a análise de conteúdo, com o objetivo de desmontar a estrutura e os elementos dos relatos nas entrevistas e demais dados coletados durante as observações. A intenção é esclarecer as diferentes características dos dados e extrair sua significação, com a possibilidade de abordar uma grande diversidade de materiais e objetos de investigação, tais como: atitudes, valores, representações, mentalidades, ideologias, etc. (LAVILLE; DIONNE, 1999). A análise do conteúdo não é um método rígido, constitui-se de um conjunto de vias possíveis, nem sempre claramente balizadas, para a revelação ou reconstrução do sentido de um conteúdo. Basicamente, a técnica consiste na organização sistemática de dados, buscando alcançar, por meio da ordenação, conteúdos ocultos pelo próprio volume e pela disposição desses dados (BARDIN, 1994).

No processo de análise dos dados, utilizou-se o sistema aberto (BARDIN, 1994), no qual a definição das categorias de classificação dos dados se dá a partir dos mesmos, de acordo com a organização dos elementos de conteúdo, agrupados por parentesco de sentido. Seguindo-se os critérios de pertinência, exaustão, número limitado de categorias, precisão e categorias mutuamente exclusivas, as categorias selecionadas foram: Shopping Popular como "casa"; Shopping Popular como "rua"; Ruas (local de trabalho do ambulante) como "casa"; e Ruas (local de trabalho ambulante) como "rua".

\section{O Shopping Popular Oiapoque}

O Shopping Popular Oiapoque foi o primeiro criado pela Prefeitura Municipal de Belo Horizonte, a fim de abarcar os comerciantes informais que trabalhavam nas ruas. Essa obra ganhou amparo com a concepção e implementação do Código de Posturas da cidade de Belo Horizonte, em 2003/2004, que visava organizar o espaço da região central da cidade. Havia a necessidade de transferir o comércio informal (vendedores ambulantes, camelôs e "toreros") para espaços específicos, denominados "Shoppings Populares" (ZAMBELI, 2006). Até aproximadamente o mês de maio de 2005, a Prefeitura Municipal de Belo Horizonte já havia colocado em funcionamento quatro shoppings populares, alocando, aproximadamente, 1.772 comerciantes informais nesses espaços. Atualmente, está em andamento a construção de novos shoppings para abrigar os demais comerciantes informais que circulam no centro da cidade. No discurso oficial da prefeitura, um dos objetivos dessa medida seria a despoluição visual da cidade.

O Shopping Popular Oiapoque, localizado à Avenida Oiapoque, $\mathrm{n}^{\circ}$ 176, foi inaugurado em agosto de 2003, sendo, portanto, uma iniciativa anterior à implementação do Código de Posturas do Município. Contudo, serviu de exemplo e inspiração à construção dos demais. Para esse shopping foram remanejados cerca de 650 trabalhadores informais que atuavam no centro de Belo Horizonte.

Os shoppings populares, conhecidos também como camelódromos, contam com o apoio da prefeitura e de setores formais da economia, como a Câmara de Dirigentes Lojistas (CDL-BH) e os bancos voltados à oferta de crédito popular a estes comerciantes (GIANNINNI, 2004; CHOUCAIR; GIANNINNI, 2004). Essa aparente aproximação entre o setor formal e o informal reforça o entendimento de que a prefeitura deseja, com esses shoppings, trazer para a formalidade o setor informal da cidade (GIANNINNI, 2004; CHOUCAIR; GIANNINNI, 2004) - responsável, atualmente, por abastecer a população local, os vendedores e comerciantes de outras cidades, além de outros, de várias regiões do país, que compram para revender em suas cidades de origem (CHOUCAIR; GIANNINNI, 2004).

A atuação econômica anterior à transferência para os shoppings sofreu, após esse processo, transformações abrangendo influências dos contornos de "formalização" que perpassam as questões simbólicas referentes ao estar, ou não, na rua. Tais aspectos envolvem a própria re-organização espacial do que antes eram atividades informais e que agora caminham para se tornarem "mercados formais", com sede fixa e legalizadas (ou pelo menos com alvará das prefeituras, pois esses espaços devem ser fiscalizados a fim de pagarem impostos àquelas). Resta questionar, dentro desse fenômeno urbano contemporâneo, as relações entre essa mudança espacial e possíveis transformações nas estratégias dos gestores envolvidos. 


\section{As estratégias nos shoppings populares: as estratégias da "casa" e da "rua"}

Trabalhar a questão da construção de estratégias relacionadas ao ambiente simbólico apresenta-se como um grande desafio, visto que há diferenças nos significados atribuídos, pelos camelôs, ao espaço shopping popular. A rua e o shopping representam simbologias de acordo com a história de vida e com as estratégias comerciais de cada organização. Utilizando as rubricas apresentadas por DaMatta (1991), tornou-se possível compreender que a diferença entre as estratégias construídas pelos gestores camelôs no Shopping Oiapoque se refere, em grande parte, ao significado simbólico que atribuem ao território que ocupam.

Para expor os caminhos que levaram a essa compreensão, serão apresentadas as diferentes estratégias construídas pelos camelôs frente às significações atribuídas ao espaço do Shopping Popular Oiapoque. Primeiramente serão analisadas as estratégias daqueles que associaram o shopping à "casa" e a rua à "rua". Em seguida, as estratégias dos que atribuem o significado de "casa" à rua e de "rua" ao shopping. Essa análise comparativa permite compreender a importância do significado simbólico na construção de estratégias, especialmente no que se refere às mudanças espaciais.

\section{Espaço simbólico 1: o shopping como "casa" e a rua como "rua"}

De acordo com DaMatta (1991), a "casa" representa um espaço que reúne pessoas com fortes vínculos sociais comuns. Os ex-camelôs, agora instalados no Shopping Oiapoque, possuem uma história de vida semelhante no que diz respeito ao trabalho informal. Eles partilham um passado nas ruas representado por dificuldades, marginalização, preconceito, repressão e pela mudança para o shopping. O relacionamento entre os ex-camelôs caracteriza-se pela união, como uma classe diferenciada. Eles usam intensamente expressões como "estamos todos no mesmo barco" e "o que afeta um afeta todos".

Os relatos de entrevistas, ilustrados nos fragmentos 1 e 2, revelam o destaque dado por parte dos sujeitos de pesquisa a aspectos negativos da época em que ficavam expostos na rua e submetidos às intempéries climáticas, por disporem de condições precárias de trabalho.

(1) Em 2002 teve uma chuva, um temporal, né? Choveu levou a... a chuva levou minha barraca. Eu perdi minha mercadoria toda. [...] (B.Z.).

(2) [...] na rua não tinha como manter (as mercadorias limpas). Às vezes o cliente chegava pra comprar e a mercadoria suja ele não comprava (M.L.).

(3) A gente montava a banca aqui embaixo e tirava a mercadoria toda do carrinho e colocava. E na hora de fechar tirava tudo e colocava tudo no caixote de nada e levava para o estacionamento e pagava para a moça de lá para guardar para gente também (J.A.).

O local de trabalho era nas calçadas e ruas do centro da cidade. Eles expunham seus produtos em barracas de metal e madeira, que precisavam ser montadas e desmontadas todos os dias. Existiam também os "toreros", que expunham seus produtos em bancas facilmente manuseáveis, para o caso de terem de fugir da fiscalização. Na rua, os camelôs não tinham como se proteger do sol, da chuva e das enxurradas, condição que prejudicava a venda e os produtos, na medida em que estes ficavam sujos de poeira, estragavam com o calor do sol e eram levados pela água da chuva. A estratégia, então, para a comercialização, era a dos preços baixos, o que era anunciado pelos próprios comerciantes, que declaravam "ganhar o cliente no grito".

Essas condições levavam ao desgaste dos camelôs, inseridos na rotina de acordar muito cedo buscar a mercadoria nos depósitos alugados (hotéis, motéis e estacionamentos do centro de Belo Horizonte), montar as barracas de forma que estivessem preparadas para os clientes que iam para o trabalho e, ao final do dia, desmontar, embalar e guardar os produtos em depósitos. 
Isso explica manifestações nas quais o shopping é visto como "casa" por parte dos ex-camelôs, pois tem uma estrutura para abrigá-los, com box fixo e portas, oferecendo maior conforto em relação aos problemas anteriores, bem como à falta de banheiros e depósitos, como revelam os fragmentos 4 e 5.

(4) Na rua nós tínhamos o quê? Nós ficávamos muito expostos, né? Não tinha como comer, beber, banheiro. Tinha dificuldade pra ir ao banheiro. Essas dificuldades. O shopping, pra gente, foi melhor. Porque aqui tem conforto, nós temos o banheiro, nós temos aonde beber a água, né? [...] Acho que aqui ficou bem melhor (B.N.).

(5) A fiscalização também era (na rua) mais. Eu perdia mercadoria direto. Agora aqui dentro é mais tranqüilo. Só de vez em quando que a polícia vem encher o saco (J.A.).

A “rua", conforme já apresentado no Quadro 1, é um local perigoso, instável, onde coisas ruins e inesperadas podem acontecer. Pode-se relacionar o apresentado no Quadro 1 ao fragmento 4, no qual a expressão "ficávamos muito expostos" permite subentender-se sujeição às intempéries e, concomitantemente, à marginalização inerente ao espaço rua, por meio da exposição social. No caso analisado, os trabalhadores informais instalados nas ruas vendem produtos não autorizados legalmente, que não pagam impostos, falsificados. Esses trabalhadores sofrem a perseguição de fiscais da prefeitura, pois não se encaixam nas formalidades impostas. Uma vez dentro do shopping, constituído formalmente pela prefeitura, a atitude da fiscalização em relação a eles se altera, pois passam a usufruir de certa legitimidade junto à instância municipal. A despeito de executarem a mesma atividade, agora atuam em um novo espaço, que os distingue sob o olhar dos fiscais. Entretanto, quando a polícia (civil, militar ou federal) está engajada em alguma ação esporádica contra a sonegação, o contrabando ou a falsificação de mercadorias, são eles o alvo principal e ainda mais facilmente controlados, pois são infratores facilmente identificáveis, com suas mercadorias ilegais livremente à mostra no interior do shopping.

A despeito dessa ilegalidade, alguns sujeitos de pesquisa revelaram que a transferência da rua para o shopping levou-os à percepção de uma redução na discriminação que sofriam por parte da sociedade, como ilustra o fragmento 6 .

(6) A gente "tava" na rua, o pessoal discriminava a gente demais [...] Pensava que a gente era, entendeu? É ladrão ou alguma coisa assim. Foi uma época muito discriminada. Só depois que a gente entrou pro shopping... Não vou dizer, assim, que melhorou 100\% não, mas uns $80 \%$ [...] (P.O.).

Essa percepção na mudança quanto à "discriminação" remete o novo espaço ocupado a um status diferenciado. Durante as observações e conversas informais, essa distinção em termos de status ficou clara, observada, por exemplo, pelo fato de parte dos sujeitos se considerarem lojistas, não mais camelôs. Alguns ainda usam ambas as representações sociais de si, como estratégia de persuasão, de acordo com seu interlocutor, pois associam o nome "camelô" ao comerciante ambulante, que não tem um lugar próprio nem boas condições financeiras (capital). Os lojistas estão em um espaço bem delimitado, têm um "endereço", enquadrando-se em regras do comércio definidas pelo município. Assim, alguns se apresentam como lojistas ao cliente, que poderá confiar no seu produto, mas alegam serem "apenas camelôs" quando reclamam das injustiças referentes aos altos custos pagos, no shopping, em aluguel e condomínio.

Outro fator importante do shopping como "casa" é a segurança que oferece aos lojistas e clientes, que não precisam se preocupar tanto com as tentativas de furto, devido à segurança oferecida pela direção do estabelecimento, como fica claro no fragmento 7.

(7) [...] aqui melhorou. Tem segurança, né? Só de ter os "muro" e os portões, os caras já pensam duas vezes antes de entrar pra roubar, né? Agora ali na rua, ali não tinha nada. Eram as bancas todas espalhadas ali. Passava quem quisesse, né? Maloqueiro, tudo. Agora aqui não. Se os cara chega todo sujo ou descalço eles já não deixam entrar pra dentro não (F.J.). 
O aumento da segurança e a "elevação de status" de camelô para lojistas são considerados como razões para que clientes de classes sociais mais elevadas freqüentem o shopping e, ainda, para que o trabalho deles, agora lojistas, contribua para a região do entorno do shopping, como fica evidente no fragmento 8.

(8) Você, querendo ou não, o shopping trouxe vida para o centro. [...] Com este shopping aí o policiamento aumentou. [...] Então a pessoa, pessoal de classe média, de classe média-alta freqüentam muito ali (J.A.).

Além da questão da segurança, a percepção do shopping como "casa" também é reforçada pelo fato de os familiares trabalharem no box e de o patrão possuir laços fortes de amizade com o empregado. Isso aproxima o local de trabalho com a simbologia da "casa". Durante as observações, ficou claro que esses laços familiares e de amizade apóiam o fazer estratégia dos gestores nas práticas sociais referentes ao controle do que se vende. Comumente, os lojistas demonstraram não ter como prática o controle direto sobre as vendas - nem das suas nem das realizadas por seus funcionários. No lugar de um controle direto, sua prática social se volta para a consolidação de uma relação na qual o funcionário é tratado como amigo, e, às vezes, como "da família". O "voto de confiança" é concedido a familiares, amigos e pessoas indicadas. Os fragmentos 9 e 10 evidenciam práticas relacionadas a essa concepção de controle.

(9) [...] Eu, desde pequeno, eu dou uma oportunidade pra pessoa, né? Se vê que ela tá pisando na bola aí num tem como você confiar mais, né? [...] Às vezes vende, deixa lá no caixa, lá. Depois eu chego de tarde pego o dinheiro, levo embora (F.J.).

(10) [...] os patrões ali têm uma relação boa com os empregados. [...] Ali dentro não tem diferença não. Se o pessoal faz festa, todo mundo convida todo mundo (J.A.).

Um outro aspecto destacado em relação ao fazer estratégia de parte dos gestores, na medida em que se inseriram no espaço do shopping, foi a introdução de duas novas práticas sociais voltadas à preocupação com o cliente: o aproveitamento das condições favoráveis de um ambiente fechado para uma maior aproximação com o cliente; e a ampliação dos espaços para expor mercadorias aos clientes - ilustrados pelos fragmentos 11 e 12 , respectivamente.

(11) Porque é um ambiente fechado, e a gente está ali num local que não tem preocupação com fiscal $e$ as outras coisas, e então fica mais fácil para você atender o cliente. Para você dialogar com ele (G.I.).

(12) Agora um lojista ainda dá para ganhar algum dinheiro, porque o cara emenda 2 ou 3 lojas e faz uma loja e aí é diferente. É mais fácil você pagar o aluguel de 3 box juntos do que o de um. Porque 3 você pode pôr mercadoria à vontade. Mas um só você fica ali espremidinho e nem visão você tem do cara não. Este que é o problema. O camelô morreu por causa disto (J.A.).

A idéia de um espaço seguro, a "casa", é associada à possibilidade de lidar melhor com o cliente nela inserido. Da mesma maneira, é desnecessário o sofrimento por falta de espaço para trabalhar, pois, além de segura, a "casa" é espaçosa. Essas, em conjunto com as construções já mencionadas, remetem à representação do Shopping Oiapoque como "casa". Construções que justificam, mesmo que parcialmente, a rápida identificação de um grupo de ex-camelôs com o shopping.

\section{Espaço simbólico 2: shopping como "rua" e a rua como "casa"}

Afastando-se da representação anterior, alguns ex-camelôs consideram que a rua era o espaço da "casa" e o shopping o da "rua". Isso influencia diretamente na forma como eles relatam gerir seus negócios e como avaliam o ambiente para a construção de estratégias. 
Para esses sujeitos, a rua era o local onde se sentiam seguros, onde se sentiam "em casa", porque era lá que podiam contar uns com os outros. No momento em que um indivíduo externo ao grupo tentasse infringir suas leis, todos se uniam contra ele. O espaço público - rua - era para esses então camelôs o seu espaço privado. Dessa maneira, eles articulavam suas práticas sociais em torno da questão da segurança, como se evidencia no fragmento 13:

(13) Para mim piorou (a segurança), porque eu e meus colegas de rua, assim, os ladrões não iam no nosso meio, porque quem ia quase morria. E hoje tem segurança aqui. Você paga um aluguel muito alto, paga condomínio altíssimo, pra ladrão ter do mesmo jeito. E não é a lei igual era a da rua. Porque camelô pegava, quase matava de tanto bater nas pragas... E eles não voltavam mais. Aqui tem direitos humanos nanananana, ai eles tão sempre voltando e você continua pagando (B.F.).

Nesse fragmento, observa-se que a territorialização (PEREIRA; CARRIERI, 2005) surge a partir do momento em que o entrevistado toma para si o espaço público como local no qual tem poder. Ele representa uma perspectiva coletiva e social, em que a união dos camelôs, na rua, fez com que se criassem leis inerentes ao território que ocupavam. Eles próprios realizavam a justiça referente a seus espaços. Quando pensa no shopping, o entrevistado o relaciona à "rua", pois diz que na rua as leis referentes aos direitos humanos prevalecem, violando as suas, a partir da atuação dos seguranças do shopping. Conseqüentemente, a contragosto, as práticas sociais dos sujeitos em questão também se aproximaram dos direitos humanos, já que não é permitido a eles atuarem, no interior do shopping, utilizando as práticas de justiça anteriores.

Ainda dentro da questão do poder, outra implicação que leva à inserção do shopping, na perspectiva da "rua", é a percepção dos então camelôs de que foram transferidos para locais nos quais o poder é exercido sobre eles e não mais por eles. Isso ocorre porque todos devem atuar dentro das normas do shopping, que são cobradas pela administração. Essa questão fica explícita nos fragmentos 14 e 15.

(14) Para falar a verdade, ficar na rua é melhor. Porque na rua não paga nada. Na rua se você quiser trabalhar, trabalha. Se você não quiser, você não trabalha. Você é o dono da rua. Aqui dentro é a pessoa que manda em você (J.A.)

(15) Você paga um aluguel muito alto, você paga condomínio. Você não tem o horário... porque você é camelô você faz o seu horário, aqui você tem horário pra entrar, você tem horário pra sair vendendo ou não vendendo, você tem que pagar (B. F.).

Observa-se que a aproximação da rua com a "casa” também envolve a questão da liberdade. É em “casa” que se tem liberdade e controle sobre o próprio tempo. E, em casa, o tempo é construído pelo grupo. Na rua as estratégias eram desenvolvidas almejando maior renda para os grupos: os camelôs iam trabalhar cedo para comercializar com aqueles clientes que estavam no caminho para o trabalho e ainda ficavam até tarde para comercializar com os que voltavam do trabalho. Ademais, nas épocas festivas que influenciam o comércio (dia das mães, dia dos pais, dia das crianças e natal), trabalhavam mais, sem se preocupar com o horário, para garantir melhores vendas. Era na rua que se fazia o horário, onde havia controle sobre o espaço e sobre o tempo.

Conforme as significações de DaMatta (1991), a "casa" é um local de conforto, de acolhimento, enfim, das relações verdadeiramente afetivas. Ao tratarem a rua como "casa", considerarem-na como espaço das interações afetivas, descobrirem nela as amizades, seu espaço próprio de poder, alguns sujeitos indicam que, para eles, a rua é a "casa". Por sua vez, o shopping é representado como o oposto à rua e o responsável por afastá-los dela. Nesse sentido, o shopping assume as significações, segundo DaMatta (1991), do espaço da "rua".

O espaço simbólico, do shopping como "rua" e da rua como "casa", se articula nas práticas sociais de sujeitos que dividem o mesmo locus, o shopping, com sujeitos que articulam em suas práticas sociais outro espaço simbólico, o do shopping como "casa" e da rua como "rua". Conseqüentemente, os dois espaços simbólicos 
coexistem e envolvem o fazer estratégia dos gestores que atuam no shopping. O primeiro grupo de sujeitos atua buscando resgatar práticas anteriores perdidas ao entrar no shopping, o que pode levá-los a abandoná-lo. Por outro lado, o segundo grupo atua buscando novas práticas, para ele o shopping não é apenas uma "casa", mas uma nova "casa", que ele busca conhecer e se inserir por meio de novas práticas. Em conjunto, as movimentações desses dois grupos de sujeitos demarcam o fazer estratégia no shopping Oiapoque.

\section{Considerações finais}

Os espaços simbólicos possuem delimitações opacas que dependem da legitimação social para se estabelecerem. Tanto o tempo quanto o espaço simbólico são construções sociais, não existem organicamente, porém estão presentes em qualquer sistema social. Corroborando esse entendimento, associado à concepção de "casa" e de "rua" de DaMatta (1991), Nicolas (1996, p. 86) explica que "[...] apropriar-se de um espaço é reconstruir sua lógica temporal, é reativar um mecanismo de articulação entre tempo e espaço diferente do anterior". Portanto, estudar as transições implica estudar espaços apropriados e desapropriados, espaços que tiverem as lógicas de tempo e organização diferenciadas de acordo com a época.

Neste artigo, percebe-se a importância da dimensão simbólica na definição de estratégias pelo gestor. Sua maior influência está na forma como ele se vê e aos outros (colegas, concorrentes e ambiente físico). Alguns, por exemplo, se denominam lojistas, outros se vêem como camelôs e outros, ainda, usam as duas representações como estratégia dentro do Shopping Oiapoque. Para os que se denominam lojistas e para os que usam as duas definições, a mudança de espaço (rua-casa) foi benéfica; tendem, portanto, a avaliar as atuais condições ambientais de seu negócio de maneira positiva, além de indicarem disposição de desenvolver novas práticas mais adequadas a essa nova "casa". Os camelôs, por outro lado, avaliam as mesmas variáveis ambientais de maneira completamente diferente, argumentando que a mudança para o shopping popular foi prejudicial aos seus negócios e buscam resgatar práticas que se perderam com a mudança.

As diferenças entre os estilos de gestão e projeções de rumo não são suficientes para explicar a diversidade encontrada entre esses gestores. Acredita-se que essa diferença se explica pela forma como os camelôs e excamelôs (lojistas) se relacionavam simbolicamente com os espaços que ocupavam (a rua) e ocupam (o shopping). As significações em relação a esses espaços criaram raízes simbólicas, fazendo com que a transferência das ruas para os shoppings populares não fosse somente um fato objetivo. Essa mudança foi carregada de elementos simbólicos nos campos da política, economia, nas relações interpessoais e nos planos pessoais. Para muitos, foi um rompimento com uma época de liberdade e ousadia e o início de uma era de sujeição. Para outros, a mudança significou o ganho de status, maior respeito pelos clientes e possibilidade de lucro. Para este último grupo, enquanto a rua era insegura, lugar da marginalidade, o shopping é o lugar dos lojistas e das classes mais abastadas. Há, ainda, outro grupo, que ora se apresenta como camelô, ora como lojista. Como camelô perante o aumento exorbitante do preço dos aluguéis, alegando não ter condições de pagá-lo. Já como lojista delineia outra estratégia, a de se apresentar como lojista no intuito de transmitir mais confiança a seus clientes, a partir do status dessa condição. Portanto, a configuração da significação subjetiva dos espaços é considerada aqui a base do processo de construção das estratégias dos gestores no Shopping Popular Oiapoque. 


\section{Referências}

BARDIN, I. Análise de conteúdo. Lisboa: Edições Setenta, 1994.

BENJAMIN, W. 0 narrador: considerações sobre a obra de Nikolai Leskov. In: Magia e técnica, arte e política: ensaios sobre literatura e história da cultura. São Paulo: Brasiliense, 1994, p. 197-221.

CANCELLIER, É. L. P. de L.; ALMEIDA, M. I. R. de; ESTRADA, R. J. S. Monitoramento do Ambiente Externo na Pequena Empresa: aplicações e limitações dos sistemas existentes. In: II ENCONTRO NACIONAL DE ESTRATÉGIA, 2005, Rio de Janeiro. Anais... Rio de Janeiro: Associação Nacional de Programas de Pós-Graduação em Administração, 2005. Texto integral em CD-ROM dos Anais do $2^{\circ}$ ES.

CARLOMAGNO, M.; BRUHN, P. R. L. Estratégia em Ambientes Complexos e Imprevisiveis. In: II ENCONTRO NACIONAL DE ESTRATÉGIA, 2005, Rio de Janeiro. Anais... Rio de Janeiro: Associação Nacional de Programas de Pós-Graduação em Administração, 2005. Texto integral em CD-ROM dos Anais do $2^{\circ} \mathrm{ES}$.

CHOUCAIR, G.; GIANNINNI, B. A informalidade abrigada: ninguém quer voltar à rua. Estado de Minas, Belo Horizonte, p. 3, 8 ago. 2004.

DAMATTA, R. A casa \&t a rua: espaço, cidadania, mulher e morte no Brasil. Rio de Janeiro: Editora Guanabara Koogan S/A, 1991. 177 p.

Carnavais, malandros e heróis: para uma sociologia do dilema brasileiro. Rio de Janeiro, Zahar, 1991.

GIANNINNI, B. Shopping Popular passa no $1^{\circ}$ teste. Estado de Minas, Belo Horizonte, p. 10, 11 out. 2004.

GONTIJO NETO, J. de P.; MACHADO, A F. 0 setor informal em Belo Horizonte: estratégia de vida ou de sobrevivência. 2003. Mimeografado.

IVO, F. B., OLIVEIRA, T. R. de. Representações Sociais em Uma Organização Familiar: o Caso Formato/Policrom. In: XXVIII ENCONTRO NACIONAL DOS PROGRAMAS DE PÓS-GRADUAÇÃO EM ADMINISTRAÇÃO - ENANPAD, 2005, Brasília. Anais... Rio de Janeiro: Associação Nacional de Programas de Pós-Graduação em Administração, 2005. Texto integral em CD-ROM dos Anais do 29 ENANPAD.

JARZABKOWSKI, P. Strategy as Practice: Recursiveness, Adaptation, and Practices-in-Use. Organization Studies, v. 25, n. 4, p. 529-560, 2004. Strategy as Practice: an activity-based approach. London: Sage, 2005.

JOHNSON, G.; MELIN, L.; WHITINGTON, R. Guest Editors' Introduction: Micro Strategy and Strategizing: Towards an Activity-Based View. Journal of Management Studies, v. 40, n. 1, p. 3-22, 2003.

LAVILLE, C.; DIONNE, J. A construção do saber. Belo Horizonte: UFMG, 1999.

LIMA, B. M. F. de. Criptoeconomia ou economia subterrânea: uma investigação preliminar no Brasil. Rio de Janeiro: Fundação Getúlio Vargas, 1985.

MINTZBERG, H. The science of strategy-making. Industrial Management Review, v. 8, n. 2, p. 71-81, 1967.

. Patterns in Strategy Formation. Management Science, v. 24, n. 9, p. 934-948, 1978.

H. Ascensão e queda do planejamento estratégico. Bookman: Porto Alegre, 2004.

MINTZBERG, H.; WATERS, J. Of Strategies, Deliberate and Emergent. Strategic Management Journal, v. 6, n. 3, p.257-272, 1985.

NICOLAS, D. H. Tempo, espaço e apropriação social do território: rumo à fragmentação na mundialização? In: SANTOS, M. et al (Orgs). Território: globalização e fragmentação. São Paulo: Hucitec, 1996. p. 85-101.

NKOMO, S. M.; COX JUNIOR., T. Diverse identities in organizational. In: CLEGG, S. R.; HARDY, C.; NORD, W. (Eds). Handbook of Organization Studies. London: Sage, 1996. p. 338-356.

PEREIRA, D. de C.; CARRIERI, Alexandre de Pádua. Movimentos de desterritorialização e reterritorilização na transformação das organizações. RAE-eletrônica, v. 4, n. 1, art. 13, 2005. Disponivel em: <http://www.rae.com.br/eletronica/index.cfm?FuseAction=ArtigoctID $=2034$ \&tSecao $=$ FOR.GEST.BCtVolume $=4$ EtNumero $=1$ \&tAno $=2005>$. 
Alexandre de Pádua Carrieri Ivana Benevides Dutra Murta

PETTIGREW, A. M. Strategy formulation as a political process. International Studies of Management \& Organization, v. 7, n. 2, p. 78-87, 1977.

REBELO, L. M. B.; ERDMANN, R. H. Aprendizagem e Subjetividade no Processo de Formação de Estratégia. In: I ENCONTRO NACIONAL DE ESTRATÉGIA, 2003, Curitiba. Anais... Rio de Janeiro: Associação Nacional de Programas de Pós-Graduação em Administração, 2003. Texto integral em CD-ROM dos Anais do $1^{\circ} \mathrm{ES}$.

SOARES, L. A.. Entre a "Casa" e a "Rua": revisitando o espaço shopping center no Brasil. In: XXIV ENCONTRO NACIONAL DOS PROGRAMAS DE PÓS-GRADUAÇÃO EM ADMINISTRAÇÃO - ENANPAD, 2000, Florianópolis. Anais... EORb. Rio de Janeiro: Associação Nacional de Programas de Pós-Graduação em Administração, 2000. Texto integral em CD-ROM dos Anais do $24^{\circ}$ ENANPAD.

THIOLLENT, M. J. M. Crítica metodológica, investigação social e enquete operária. São Paulo: Polis, 1987.

WHITINGTON, R. Strategy as Practice. Long Range Planning, v. 29, n. 5, p. 731-735, 1996.

WILSON, D.; JARZABKOWSKI, P. Pensando e agindo estrategicamente: novos desafios para a análise estratégica. Revista de Administração de Empresas, v. 44, no 4, out./dez. 2004.

ZAMBELI, P. H. L. O Trabalho Informal dos Camelôs da Região Central de Belo Horizonte e a Transferência Para os Shoppings Populares. 2006. 190f. Dissertação (Mestrado em Ciências Sociais) - Pontifícia Universidade Católica de Minas Gerais. 